\title{
Psychological Distress, Terrorist Involvement and Disengagement from Terrorism: A Sequence Analysis Approach
}

\author{
Emily Corner ${ }^{1,2}$ (D) Paul Gill ${ }^{2}$
}

Published online: 1 August 2019

(C) The Author(s) 2019

\begin{abstract}
Objectives This paper utilizes probability-based modelling to unpack the complex and multifaceted individual, sociological, and psychological processes present within terrorist groups which may affect an individual's psychological wellbeing. We outline the predictors of the onset of psychological distress across three phases of terrorist involvement (engagement, disengagement, and post-disengagement).

Methods Utilizing a dataset of over 90 terrorist autobiographies, we conduct sequence analyses to pinpoint the onset of psychological problems and the experiences that preceded and proceeded this onset.

Results The results demonstrate the complexity in the relationship between mental disorders and terrorist engagement and the heterogeneity of the lived experience of 'being' a terrorist. The experience of psychological distress is mediated by numerous factors and the combination of these factors.

Conclusions The results helped highlight the complexity of 'being' a terrorist; multiple factors at individual, social, and group levels impact on an individual as they pass through life. Individuals engaged within terrorism encounter a number of risk factors, which if an individual has lower baseline levels of individual resilience and is not fully committed to the group identity, may impact them psychologically. The results highlighted that it is not the presence of risk factors which impact on an individual, but how they perceive these risk factors.
\end{abstract}

Keywords Terrorism $\cdot$ Psychopathology $\cdot$ Protective factors

Emily Corner

emily.corner@anu.edu.au

Paul Gill

paul.gill@ucl.ac.uk

1 Centre for Social Research and Methods, Australian National University, Canberra, ACT 2600, Australia

2 Department of Security and Crime Science, University College London, London WC1H 9EZ, England, UK 


\section{Introduction}

Academic approaches to understanding the role, if any, of psychopathology in terrorist engagement greatly changed in the past few decades. ${ }^{1}$ This included positions positing psychopathy and particular personality traits in the 1970s and 1980s, to a large scale abandonment of such variables in the 1990s and early 2000s, and now to an emerging empirical literature which measures prevalence rates, disaggregates across different disorders, and compares prevalence rates across different types of terrorists and terrorist contexts (see Gill and Corner 2017 for a full review). Indeed, mental disorders and psychological vulnerabilities are now commonly incorporated into violent extremist risk assessment (Corner et al. 2019).

However, a number of limitations remain with our current understanding of the relationship. First, nearly every study examining this relationship look at the impact of mental disorder upon terrorist engagement. With the exception of Weatherston and Moran (2003), nobody has looked at the other side of the story: the impact of terrorist activity upon mental wellbeing. Weatherston and Moran's comprehensive account of former terrorists qualitatively demonstrates how the terrorist lifestyle and group conflict are fundamental variables which may contribute to the emergence of mental disorders in terrorists. They highlight that exposure to such conditions is not necessarily conducive to developing a specific mental disorder in every case, but these factors do have the potential to contribute to symptoms of mental disorder in particular individuals. Second and relatedly, despite the rise in research and policy interest in desistance and disengagement from terrorism, ${ }^{2}$ we know very little about how psychopathology might spur such decisions or be impacted by the actual disengagement itself. Third, there is a growing consensus we need to disaggregate across terrorist roles in much the same way the criminological literature disaggregates across different crime types (Gill and Corner 2013). However, with the exception of studies focused on the suicide bomber (Merari 2010) or the more general category of lone-actor terrorist (Corner and Gill 2015; Corner et al. 2016), there remains a lack of interest regarding other role types, responsibilities within an organization, and the effects of these factors on a recruit's mental wellbeing. Finally, despite being included in many violent extremist

\footnotetext{
1 The psychiatric and psychological literature utilises multiple terms to describe psychopathology. The most popular include; mental disorder, mental illness, mental health, mental deficiency, or mental retardation. The terms psychiatric and psychological are used interchangeably with 'mental' across each term. Psychiatric refers to the "relating to mental illness or psychiatry" (Collins English Dictionary 2015), and psychological "of affecting, or arising in the mind; related to mind or mental or mental activity" (Collins English Dictionary 2015). The literature often uses the terms interchangeably but there remain differences in opinion regarding the 'correct' terminology. The term mental illness is contentious among practicing mental health professionals as some consider personality disorders not to fall under the definition. Developmental and intellectual (mental retardation) disorders are also often considered outside the remit of the term mental illness. However, both the ICD-10 and DSM-V's classification systems include all these disorders (APA 2013; WHO 2010). Mental health is also an erroneous term, unless suffixed with nouns such as 'condition', 'problem', or 'issue'. Since the term mental disorder encapsulates all disorders under the ICD-10, and is currently widely accepted as appropriate, this research uses that terminology to describe specific, diagnosed psychopathology.

2 Defined as "The use or threat of action where the use or threat is designed to influence the government or to intimidate the public or a section of the public and/or the use or threat is made for the purpose of advancing a political, religious or ideological cause. Terrorism can involve violence against a person, damage to property, endangering a person's life other than that of the person committing the action, creating a serious risk to the health or safety of the public or a section of the public, or facilitating any of the above actions." (Gill et al. 2014).
} 
risk assessment tools, there is a need to further understand comorbidity with other problems. Indeed, LaFree et al. (2018, pp. 21) note that "future research should be aimed at seeking more precise data sources to unpack the nuances in the relationship between mental illness and violent extremism, especially when it coincides with other potentially compounding factors such as substance abuse, criminal history, and emotional trauma."

To contribute toward these knowledge gaps, this paper uses data from over 90 terrorist autobiographies and conducts probability-based behavioral sequence analyses. Similar sequence analyses focused on alcohol-related violence (Taylor et al. 2017), hostage negotiations (Taylor and Donald 2007), rape (Fossi et al. 2005), serial killing (Keatley et al. 2018a, b) and lone-actor terrorist mobilization (Corner et al. 2019) have demonstrated the roadmap(s) through which behaviors sequentially interacted to produce the outcome behavior (Taylor et al. 2008). ${ }^{3}$ In particular, this paper examines sequences of experiences and risk factors within a terrorist group, why these factors may lead to terrorist disengagement, and the challenges and risks former terrorists face following disengagement.

\section{Theory}

Before introducing our data and method, this section outlines the current state of knowledge on the risks of the terrorist lifestyle to mental wellbeing, why terrorists disengage, the risks associated with disengagement, and post-disengagement terrorist lives.

\section{Risk Factors Within Terrorist Groups}

The terrorist lifestyle involves exposure to similar violent and traumatic situations found in military entities. The process of experiencing continuing violence may lead to changes in cognitive processes that later affect their mental wellbeing. Like military groups, individuals involved in terrorism may also experience psychological responses to their individual actions as well as group activity (Weatherston and Moran 2003).

Both the military and criminal offender literature focus on traumatization following violence towards others. Byrne (2003) explained how self-appraisal of events may influence the onset of psychological distress ${ }^{4}$; if an individual carries out an action that violates their underlying belief system, the individual is more likely to experience trauma. Neuner et al. (2012) verified this by explaining how distress symptoms were more likely to manifest in child soldiers who were abducted and forced to act violently. Turner and Avison (1992) supplemented this in explaining how only experiences perceived by an individual as 'unresolved' [unable "to derive positive meaning for themselves and/or their futures" (Thoits 1995, pp. 58)] are linked to distress symptoms. Intrinsically linked to these theories, other studies purport guilt and shame as an important mediating factor in the development of post-traumatic stress disorder (PTSD) symptoms (Crisford et al. 2008; Leskela et al. 2002).

\footnotetext{
${ }^{3}$ For a full introduction to behavioural sequence analyses and their methodological principles, see Taylor (2006) and Keatley (2018).

${ }^{4}$ Defined as the range of symptoms that may concern, confuse, or trouble an individual. Psychological distress has a wider remit than mental disorder, as it does not require a specific set of medically defined attributes. An individual suffering from psychological distress may exhibit some symptoms commonly identified across mental disorders. These symptoms may resolve without medical intervention; however, the longterm experience of such symptoms may lead to the diagnosis of a specific mental disorder. Life events influence the onset of psychological distress.
} 
This evidence helps explain why a proportion of individuals who undergo the same experiences may not experience distress. Byrne (2003) also proposed that differences in offence type (planned vs. unplanned) may influence the onset of PTSD symptoms. Byrne further suggests that individuals who see the offence resulting from a loss of control were more susceptible to PTSD symptoms.

Alongside violence and trauma, there are other endemic social factors within terrorist organizations that have the potential to negatively affect the mental wellbeing of individual members. Intra-group competition produces conflict, leading to personal animosities at the lowest level and to group fissioning at the highest (as seen in Irish Republican movements) (McCauley and Moskalenko 2008). The pressure to bow to a seemingly unanimous majority can create intense interpersonal conflict, leading to paranoia, aggression, and delusions (Weatherston and Moran 2003). Punishment for defectors and those who do not conform to the group rules, whilst enhancing the competitive advantage of the group, can severely psychologically impact those who are punished (Gürerk et al. 2006). Finally, internal mistrust within a group also feeds intra-group tensions. As relationships strain, ideological drift can occur (Borum 2011).

\section{Why do Terrorists Disengage?}

Desistance from terrorism, whether as a collective or an individual has received a moderate amount of attention in the literature. Ross and Gurr (1989) identified both internal and external factors which contribute to collective disengagement. They listed four factors; preemption, deterrence, burnout, and backlash. Each of these factors has the potential for playing a role in disrupting the social identity ${ }^{5}$ of the group and fissioning the internal bonds. Miller (2012) highlights a number of other investigations which also developed typologies for desistance (Crenshaw 1991; Cronin 2006, 2009; Jones and Libicki 2008; United States Institute of Peace 1999). Miller explained that despite differences in terminology and complexity, each model was concordant that group desistance results from both internal and external influences, and results from multiple factors operating simultaneously.

There is also consensus among academics that individual disengagement from terrorism is facilitated through a variety of mechanisms. Reinares (2011) proposed that disengagement results from structural, organizational, or personal factors. Reinares conducted 35 interviews with former members of Euskadi Ta Askatasuna (ETA), reporting that until the mid-1980s decisions to desist from terror activities spanned from personal perceptions of political changes. After the 1980s however, the overarching reasoning behind desistance was due to internal disagreements concerning leadership. Reinares also highlighted that throughout the timeframe analyzed, there were a selection of members that voluntarily left due to 'personal' reasons. Of those interviewed, the majority of former actors who left the organization citing individual motivations had been incarcerated prior to their desistance. Reinares does not provide further expansion of 'personal reasons', other than mentioning a former female member who was motivated to leave the organization due to fatigue and

\footnotetext{
5 The identity of social groups has been frequently discussed in the literature. Identity fusion (Swann et al. 2012) occurs as a consequence of a group's shared identity. In identity fusion, the boundaries, which normally demarcate the personal and social self, become highly porous, allowing aspects of both the personal and social self to cross over, without reducing the integrity of either self. This results in robust feelings of connectedness with both the group and group members. These strong feelings nurture relational ties to others within the group.
} 
"existential crisis" (pp. 799). Despite the worth of this investigation, the author appears hesitant to expand on the meaning of 'personal' nature. This might be due to the small sample and the potentially exponential number of personal reasons behind disengagement.

Altier et al. (2017) do expand on 'personal reasons'. In their statistical analyses of terrorist autobiographies, they include burnout, psychological distress, fear, regret, coping, experience of being a victim, physiological distress, desires to marry, have children, seek education or employment, difficulties in balancing family life, and family and friends convinced the individual to leave. Altier et al. concluded that 'push factors' (specifically disillusionment with tasks, and disagreements with group leaders, other members, and strategies) play a major role in disengagement. Altier et al.'s work is also supported by Horgan (2009), who described psychological and physical influences experienced by terrorists, and Bjørgo, (as cited by Mullins 2010), who discussed push (dissatisfaction with group) and pull (alternative attractions) factors, and classified 'burnout' ${ }^{6}$ as a factor affecting disengagement. Rabasa et al. (2010) explain how the probability of disengagement is inversely related to the degree of commitment to the group.

Risks in Disengagement When an individual disengages from a terrorist group, their external social alternatives are greatly diminished. They are isolated from other, previously secure social groups. The anticipation of this isolation catches some in a self-perpetuating cycle; without a secure social group to support them, they stay within the group, and maintain the psychosocial connections. Demant et al. (2008) support this, highlighting that loyalty to comrades can act as a barrier to disengagement. This loyalty helps to maintain fusion with the group and affects an individual's willingness to replace their old belief system with something new. Swann et al. (2012) highlight that due to these factors, de-fusion from a group can be highly psychologically damaging, as an individual will need to restructure their personal relationships, and even the meaning behind their own actions.

Gunaratna (2009) explains how following a break from the social identity, the former terrorist is left isolated from the non-terrorist society. This breakdown of relationships within a social environment can act as a detrimental stressor on individuals' cognitive functioning (Broadhead et al. 1983; Kessler et al. 1985). Breakdowns in social relationships can also remove an important buffer to other stressors. Ystgaard et al. (1999) highlighted that negative life events had a significantly stronger effect on mental health in males when social support was low. Haslam and Reicher (2006) examined the effects of social identity on psychological distress. As the participants sense of shared identity increased, so did the levels of social support, which protected individuals from the adverse effects of stress. However, as the participants' shared identity fragmented, there was a withdrawal of social support, and the participants felt the detrimental effect of stressors. Additionally Evans et al. (2004) statistically examined the effects of social fragmentation on individuals, identifying high psychiatric morbidity in socially fragmented areas. Donald and Dower (2002) examined risk and protective factors for depression, highlighting that social connectedness was the most important ameliorating factor for depression in males. These investigations highlight the importance of social bonds. Individuals who are no longer engaged within terrorist groups have not only lost their social identity, but they are also often struggle with

\footnotetext{
6 First defined by Freudenberger (1974) as “a state of mental and physical exhaustion". The concept, originally developed for working health professionals, has now been expanded across multiple domains.
} 
guilt over their actions from engagement. The next section examines how former terrorists cope with these major stressors.

Risks Post-disengagement Terrorist groups offer social support, and often legitimize their violent acts by viewing themselves as genuine military entities. The above sections also highlighted that following fragmentation of a social identity, individuals are at risk of experiencing psychological distress. It would therefore not be surprising to see symptoms of PTSD and other mental disorders following attempting social reintegration and functioning in a non-military society. Alongside the complex psychological mechanisms, social processes play a key role in understanding the occurrence of PTSD and associated symptoms. Muldoon and Lowe (2012) argue social identity is crucial in understanding the role of group-level factors on individual attitudes, behavior, and mental health. PTSD should not be viewed as occurring in a vacuum, instead the disorder and associated symptoms need to be viewed as an individual operating in a particular social context following a traumatizing event.

Supporting evidence for PTSD as a social phenomenon has been shown across individuals and groups. Li et al. (1998) examined distress symptoms in a cohort of adolescents living in an underdeveloped area. They highlighted that the factors most commonly associated with distress following exposure to violence were 'intrusive thoughts/feelings', 'distraction', and 'lack of belongingness'. 'Lack of belongingness' is particularly pertinent, as it highlights the importance of social support in alleviating distress. Hobfoll et al. (2006) highlighted how individuals exposed to terrorist violence who had sustained social support were less likely to develop depression or PTSD symptoms. Kaniasty and Norris (2008) highlighted that individuals who have chronic, long standing psychological distress following trauma, are vulnerable to social selection- a lack of social support spanning from a lack of recovery in a socially accepted timeframe, leading to introversion and feelings of detachment. Keane et al. (1985) demonstrate that war veterans with PTSD symptoms, more likely suffered from a gradual removal of multiple outlets of social support over time as compared to non-traumatized veterans. Solomon and Mikulincer (1990) uncovered a similar phenomenon in Israeli soldiers. Those with more severe PTSD symptoms one year after the 1982 Lebanon war, were more likely to have lower social support at a 12 month follow up. Schützwohl and Maercker (2000) investigated former East German political prisoners and concluded that PTSD symptoms avoidance and emotional numbing negatively influenced perceived social support. Kotler et al. (2001) compared patients with PTSD, respondents with non-PTSD anxiety disorders, and healthy controls. Patients with PTSD recorded the lowest perceived social support scores. Zerach et al. (2013) performed a 20-year longitudinal study with military veterans. Veterans who experienced combat were more likely to suffer psychological distress across the time period, as compared to non-combat veterans. Alongside this, combat veterans' post-traumatic stress symptoms in early follow-up were significant predictors of poor family cohesion in later follow-up. Lower family cohesion also significantly impacted on later post-traumatic symptoms. This bi-directional relationship highlights the difficulties individuals with post-traumatic symptoms face.

Research is starting to uncover the longstanding psychological consequences of being a member of a terrorist group. This work currently principally investigates veterans of Irish Republican and Unionist groups. McEvoy et al. (2004) reflected on the post-incarceration periods of ex-Republicans. At least $75 \%$ of respondents showed symptoms of PTSD, with almost $60 \%$ reporting poor emotional wellbeing. There was also high reporting of individuals facing great difficulties in re-establishing fractured familial 
relationships. Jamieson et al. (2010) investigated the well-being and social and economic inclusion of former political prisoners in Northern Ireland. This report concluded that $39.9 \%$ of respondents met criteria for clinically significant mental disorders, over half reported PTSD symptoms, $45.2 \%$ described suicidal ideation since release from prison, $68.8 \%$ met criteria for hazardous levels of alcohol consumption, with $53.3 \%$ meeting the threshold for alcohol dependence. The respondents did continue to show high levels of psychological resilience, ${ }^{7}$ but this was concurrent with significant psychological harm and emotional consequences spanning from the conflict.

The above review highlights the worth of examining psychological distress (and subsequent mental disorder) within individuals engaged in terrorist groups. There are multiple risk factors across the process of 'being' a terrorist; from activities and roles whilst engaged, to the fracturing of relationships during disengagement, to re-learning how to function in a society they fought to change.

\section{Data}

We utilized terrorist autobiographies to solicit relevant information regarding the terrorist life course. Autobiographical information is heavily reliant on autobiographical memory. Autobiographical memory plays a critical role in the construction of individual identity, accounting for what occurs, and when in a lifespan. Given this, systematic analysis of terrorist autobiographies has the potential to offer understanding of psychogenesis, thought processes, reasoning, and social construction over a life course, an advantage not afforded in prevalence studies (Altier et al. 2012, 2017). Analysis of autobiographical data also limits participant reactivity via (a) removal of contamination effects found in observation studies (b) elimination of researcher-participant interactions, (c) removal of expectancy bias from participants, and (d) reduction of artificiality found in interview designs (Altier et al. 2017; Krippendorff 2004).

A major issue with autobiographical data is source reliability. Autobiographical memory is fragile and fades over time (Berney and Blane 1997; Rubin et al. 1986; Walker et al. 1997). Work on mood-state-dependent memory highlights that memories are more effectively recalled if the mood at recall matches the mood at learning, and if individuals are in a positive rather than negative mood (Ucros 1989). As many autobiographies examined were written post-engagement, and recalled unpleasant, sometimes horrific events, it necessitated cross-checking information with historical records to identify potential inaccuracies. Despite weaknesses, there are merits to using autobiographical data to investigate terrorist behavior. Reminiscence bumps occur in autobiographical memory recall due to the novelty and stability of events occurring in early adulthood, and thereby produce a higher chance of autobiographical recall in later life (Conway and Pleydell-Pearce 2000; Rubin et al. 1998). Indeed, Conway and Haque (1999) discerned that reminiscence bumps occurred in adults who had personally experienced a period of national conflict.

A larger concern is the potential for bias in autobiographical accounts. Wilson and Ross (2001) highlight that autobiographical memory recall is skewed by the need for self-enhancement, permitting individuals to maintain favorable views of themselves and

\footnotetext{
7 The concept of internal psychological resilience as a protective factor against developing psychological distress will be explored further in an upcoming publication.
} 
their actions. Terrorists often attempt to re-characterize their actions as legitimate and can use their writings to put forth their ideology and tactical suggestions (Cordes 1987; Ross 2004). Despite these concerns, autobiographical accounts have the potential to offer significant insight into behavioral processes at any point in time during a life span, and can offer more revealing information than intended (Altier et al. 2017).

We used Shapiro's (2013) bibliography as an initial source for identifying potential autobiographies. This yielded 108 autobiographical texts. Within this dataset, autobiographies were chosen for inclusion based on language (English and translated documents), timeframe (due to text availability, individuals active prior to 1900 were removed), admission of action, and availability. Due to time and resource constraints, only documents that were in print or available through libraries were considered. Accounts only providing brief timeframes were excluded (e.g. Donal Donnelly, Prisoner 1082: Escape from Crumlin Road, Europe's Alcatraz; Bobby Sands, A Day in my Life), ${ }^{8}$ as were texts that portrayed an overview of the organization rather than an account of their personal journey (e.g. Naim Qassem, Hezbollah: The story from within). These criteria yielded 80 texts. Following this, further texts were sought using online repositories, bookshops, and libraries using the same initial criteria. This left 97 autobiographical accounts from 91 individuals for analysis.

The 97 autobiographies covered a range of group ideologies including ethno-nationalism (61.5\%), left-wing (22\%), right-wing (6.5\%), religious (4.5\%) and single-issue (0.9\%). "Appendix 1" also names the militant organisations, and the frequency of their inclusion, which the actors in this dataset stated that they joined during their involvement.

This research used a codebook developed to examine the life course of terrorists. The codebook contained 197 questions, covering; early life experiences, mental health problems, recruitment, roles and experiences whilst engaged, disengagement, post-disengagement experiences, and stressors. These questions were derived from previous codebooks used for open source data collection (Gill et al. 2014), autobiographical data collection (Altier et al. 2017), and literature on terrorist engagement and disengagement.

Due to the sensitive nature of specific subjects, such as abuse and mental disorder, there was an inherent lack of disclosure. In these cases, it was necessary to deduce possible occurrences from available information. If a source spoke at length concerning their negative psychological state, but never directly gave any diagnostic information, this information was coded as 'psychological distress'. Examples of psychological distress include Ingo Hasselbach's suicidal ideation; "I started to think of hanging myself that night." (Hasselbach and Reiss 1996, pp. 330) and Susan Stern's continuing mental health problems; "I flopped around doing nothing for 2 weeks, sunk in melancholy. I continued taking downers. I drank-anything to relieve my misery, to allow me to sleep" (Stern 1975).

Coding included direct transcription from the source matched to the relevant question, with the date of the occurrence included, and a page number. Only information directly presented in the source was utilized. If an extract was appropriate for multiple questions, it was transcribed for each. This top-down approach to coding has advantages over other more subjective coding, such as grounded theory (Corbin and Strauss 1990) which can be hampered by subjective opinion. The first author coded each of the texts. To ensure reliability, an independent coder was trained on the coding procedure but left blind to the

\footnotetext{
${ }^{8}$ As the analyses conducted were examining distinct phases in a life course, autobiographies chosen for analysis gave insight into early life experiences, periods prior to engagement, during engagement, and post disengagement. Autobiographies which did not include writings on these periods were not taken forward for examination.
} 
research hypotheses. The second coder independently coded seven (7.2\%) autobiographies. The reliability of coding achieved $82.1 \%$ agreement, and a corresponding Cohens Kappa of 0.73 , suggesting substantial coding reliability (Viera and Garrett 2005).

\section{Method}

In comparing those who did and did not self-report psychological distress, Chi Square and associated Fisher's Exact Tests identified if certain negative experiences correlate with the presence of psychological distress whilst engaged in terrorist activity and following disengagement.

Terrorist experiences, processes, and actions are inconsistent. Inferential statistics typically focus on the relationship between immediate events. However, human behavior is often much more complex than such simple mono-causal interactions imply. Often immediate behaviors or experiences within a sequence are related, but only after one or more behaviors earlier in the sequence. It is imperative to capture the more indirect behaviors and experiences, as these may be critical to how a process develops (Taylor and Donald 2007). Therefore, it is necessary to utilize an empirical methodology which identifies common processes, whilst also retaining the complex individual processes. Proximity coefficients achieve this by measuring the average immediacy with which particular behaviors follow one another across a sample of sequences (Beune et al. 2010; Giebels and Taylor 2009; Taylor 2006).

The proximity coefficient helps identify the collocation of behaviors across a sample of interactions. The proximity coefficient offers a more complex understanding of chains of behaviours than so called 'lag one sequence analyses' which are more typically used in the literature (Ellis et al. 2017) and are therefore more suitable to our life course approach. Lag-one analyses take an antecedent behaviour ('a') and a sequitur behaviour ('b') and tests whether the latter occurs directly after the former more frequently than expected by chance (Ellis et al. 2017) This is carried out repeatedly across each possible behaviour pair. Whereas lag-one analyses can only look at the interdependence between relationship pairs (e.g. $\mathrm{A} \rightarrow \mathrm{B}, \mathrm{B} \rightarrow \mathrm{C}$ and $\mathrm{C}-\mathrm{D}$ ), proximity coefficients can look at interconnectedness across a full chain (e.g. $\mathrm{A} \rightarrow \mathrm{B} \rightarrow \mathrm{C} \rightarrow \mathrm{D}$ ) (Taylor 2006). For example, the proximity coefficient is 0.00 if the behaviors under scrutiny always occur at opposite ends of the sequence. However, if one node immediately precedes another, the coefficient is 1.00 regardless of where this occurred in a given sequence. Values between 0.00 and 1.00 reflect the different levels of proximity between two nodes being examined across multiple sequences. They are independent of sequence length (weightings reflect absolute distances across sequences) and node occurrence frequency (Beune et al. 2010). The interpretation should focus on the onset of a behavior rather than when its influence weans as is typical for sequence analyses (Taylor 2006).

To generate the proximity coefficients, experiences within each autobiography are assigned a code (e.g. if an individual described an incidence of physical abuse, it was coded as PhysAbuse). These codes are then arranged in chronological order, starting with the earliest reported experience. Each case is then analyzed and a matrix is computed. An example of a proximity coefficient matrix is highlighted in Table 1 . The ten experiences within the sequence are denoted by letters, and the matrix shows the coefficients. As per Wadman et al. (2017), rows depict antecedents and columns depict sequiturs. For example, within the sequence $\mathrm{C}$ only occurs once, and is directly preceded by $\mathrm{A}$, therefore within the matrix the proximity coefficient for $\mathrm{C}$, when preceded by $\mathrm{A}$ is 1 . $\mathrm{C}$ is not preceded by any other letter, so the rest of the column for $\mathrm{C}$ is empty. Because $\mathrm{C}$ precedes eight other letters, the row for $\mathrm{C}$ highlights numerous coefficients, which decrease in value as the sequence develops. 
Table 1 Behavioural sequence and resulting proximity coefficient matrix

\begin{tabular}{lllllll}
\hline Behavioural sequence & Behaviour-type & \multicolumn{6}{l}{ Behaviour-type } \\
\cline { 3 - 7 } & & A & B & C & D & E \\
\hline A C E D D B E A B E & A & 0.250 & 0.750 & 1 & 0.750 & 0.875 \\
& B & 0.875 & 0.750 & - & - & 1 \\
& C & 0.375 & 0.625 & - & 0.875 & 1 \\
& D & 0.688 & 0.938 & - & 1 & 0.812 \\
& E & 0.750 & 0.812 & - & 1 & 0.688 \\
\hline
\end{tabular}

The matrix is designed to be interpreted with behaviour types in the rows as the antecedents in the sequence

To evaluate whether the observed proximities are likely to have occurred by chance (e.g. whether the probability of imprisonment following arrest and criminal behavior is higher than that expected under the null hypothesis), the sequence is statistically compared across the dependent variable on two or more conditions (in this case, psychological distress and nonpsychological distress). The resulting test statistic is then compared to a set of statistics computed following randomization. A randomization test (Giebels and Taylor 2009; Taylor 2006) shuffles the derived coefficients between the two groups (psychological distress and non-psychological distress) and calculates a test statistic. This calculation is permuted 10,000 times, with test statistics calculated for each randomization. This produces a range of test statistics that might have been expected if the sequence were random. This range is then assessed to determine the probability of obtaining the original sequence (criminal, arrest, imprison) and test statistic. The fewer times the observed test statistic appears in the randomized series of statistics, the lower the resulting probability ( $p$ ) value (Giebels and Taylor 2009).

\section{Results}

\section{Descriptive Results}

Thirteen (11.9\%) individuals disclosed they suffered from a mental disorder at some point during their life span. This figure is unexpected in the sense that it sits below the general population average of $25 \%$. This may be due to a number of factors. First, it may be due to the earlier predicted lack of disclosure by the autobiographers. Second, it may be due to cultural differences. Autobiographies were taken from multiple countries, and as highlighted by Kessler and Ü̈stün (2008), mental disorder prevalence differs greatly across countries. Third, it may be due to a lack of official diagnoses (if the individual never sought professional advice for their distress).

Table 2 highlights the prevalence rates both for mental disorder and psychological distress. Table 3 presents correlation coefficients and frequencies of reported distress. $71.4 \%$ of terrorists who suffered psychological distress prior to engagement in terrorism also suffered distress during involvement. $66.7 \%$ who suffered prior to engagement continued suffering distress following disengagement. $70 \%$ who suffered psychological distress during engagement also suffered in the post disengagement period. Spearman's rho coefficients demonstrate significant positive effects, but these effects are low, highlighting the importance of considering the impact of external factors on the psychological wellbeing of individuals. 
Table 2 Prevalence differences in mental disorder and psychological distress

\begin{tabular}{llll}
\hline $\begin{array}{l}\text { Prevalence } \\
\text { Mental disorder }\end{array}$ & $\begin{array}{l}\text { Psychological distress prior } \\
\text { to terrorist engagement }\end{array}$ & $\begin{array}{l}\text { Psychological distress dur- } \\
\text { ing terrorist engagement }\end{array}$ & $\begin{array}{l}\text { Psychological distress } \\
\text { during post-disengagement } \\
\text { period }\end{array}$ \\
\hline $11.8 \%$ & $23.1 \%$ & $45.9 \%$ & $41.9 \%$ \\
\hline
\end{tabular}

\section{Risk Factors Within Terrorist Groups}

Table 4 highlights the experiences significantly associated with the suffering of psychological distress during engagement in terrorist activities. Such individuals were significantly more likely to also report physiological distress directly due to their experience as a terrorist $\left(\mathrm{X}^{2}(1)=9.630, p=0.002, \mathrm{OR}=5.082\right)$. This includes insomnia, vomiting, stomach ulcers, and becoming physically ill whilst engaged $\left(\mathrm{X}^{2}(1)=5.128, p=0.024\right.$, $\mathrm{OR}=2.471$ ). Individuals who experienced psychological distress whilst engaged were also significantly more likely to report guilt over their actions, and those of the group $\left(\mathrm{X}^{2}(1)=8.006, p=0.005, \mathrm{OR}=4.157\right)$, express regret over their actions and those of the group $\left(\mathrm{X}^{2}(1)=7.723, p=0.005, \mathrm{OR}=3.827\right)$, and report that they had trouble coping with their role and actions $\left(\mathrm{X}^{2}(1)=4.226, p=0.040, \mathrm{OR}=3.438\right)$. Individuals who experienced psychological distress were also significantly more likely to report having problems living a clandestine lifestyle $\left(\mathrm{X}^{2}(1)=11.211, p=0.001\right.$, $\left.\mathrm{OR}=4.616\right)$, and report that they were 'burnt out' due to their experiences and lifestyle $\left(X^{2}(1)=11.947, p=0.001\right.$, odds $\left.=4.243\right)$. Despite these differences between individuals, there were other stressful experiences that yielded no significant differences. There were no differences found between psychological distress and undertaking a violent role, being a victim of violence, being disrespected, being incarcerated, being abused whilst incarcerated, the death of close family or friends, substance abuse, or satisfaction with their role within the group.

Transcriptions from the autobiographies evidenced multiple reasons for distress, from suicidal ideation, loneliness (Yousef 2010), torture (Dingake 1987), familial death (Daumantas 1975; Mandela 1995), reflections on violent actions (Collins 2002; Fulton 2008; Hasselbach and Reiss 1996; Nasiri 2006), a loss of belief in ideology (Collins 1998), and the removal of social bonds outside the group (Cabezas 1985; Stern 1975). The range of experiences and attribution of distress highlights the need to examine how different experiences affect individuals over time. Tables 5 and 6 present the proximity coefficients for the above significant behaviors for individuals who did and did not suffer from psychological distress when engaged. Overall Tables 5 and 6 highlight the importance of the significant behaviors from Table 3 in the manifestation of psychological distress.

Table 5 shows that for individuals who did not report suffering from psychological distress, the majority of experiences did not occur within a sequence. This is particularly true of burnout, which is not associated with any other behavior. Within this cohort, guilt immediately preceded trouble coping with actions, which was itself immediately followed by physiological distress. This combination of experiences shows how, even when individuals did not disclose psychological distress, they are negatively impacted by their journeys through terrorism. This is further supported by the evidence which shows that physical illness occurred following a range of specific stressors, physiological distress, guilt over actions, and problems with living a clandestine lifestyle. This behavior string suggests that 


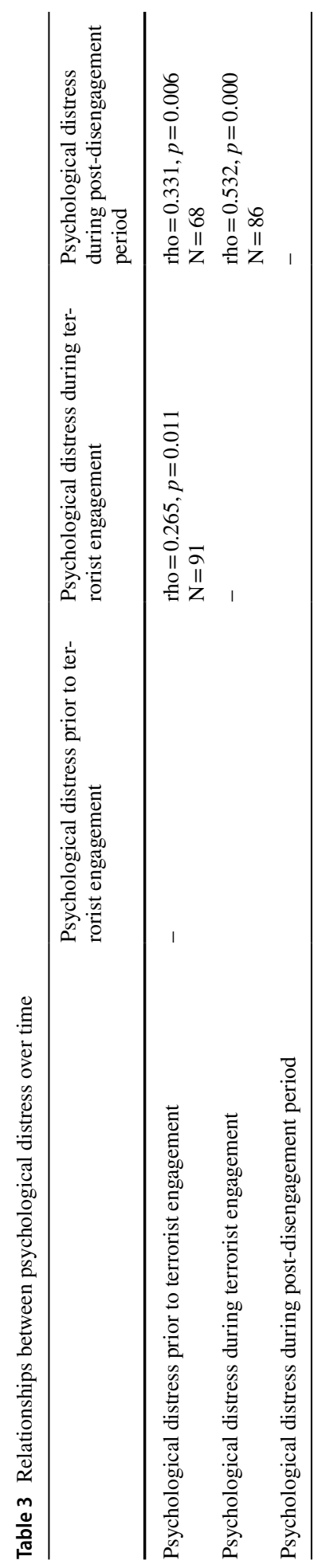


Table 4 Significant associations between stressors and psychological distress

\begin{tabular}{llc}
\hline Experience & $\begin{array}{l}\text { Frequency psychological dis- } \\
\text { tress } \mathrm{N}=50(\%)\end{array}$ & $\begin{array}{l}\text { Frequency no psycho- } \\
\text { logical distress } \mathrm{N}=59 \\
(\%)\end{array}$ \\
\hline Physiological distress & $32.0^{* * *}$ & 8.5 \\
Guilt over actions and group actions & $32.0^{* *}$ & 10.2 \\
Regret for actions and group actions & $34.0^{* *}$ & 11.9 \\
Trouble coping with role and actions & $20.0^{* *}$ & 6.8 \\
Trouble with a clandestine lifestyle & $42.0^{* * *}$ & 13.6 \\
Became physically Ill whilst engaged & $50.0^{*}$ & 28.8 \\
Burnout & $52.0^{* * *}$ & 20.3 \\
\hline
\end{tabular}

$* p<0.05, * * p<0.01, * * * p<0.005$

in some cases, physical illness may be a physical manifestation of deep seated psychological distress.

Table 6 highlights how multiple stressors have very similar, high associations with psychological distress. Psychological distress did precede stressors, but it was more closely associated with following all stressors. Psychological distress was also more closely associated with following all other stressors than physiological distress. Burnout was more likely to be a consequence of stressors, and in every case, immediately followed regret of actions. However, trouble coping also immediately followed regret. This result highlights the complexity of behavior strings within the cohort.

Further inferential analyses were conducted to determine whether there were betweengroup differences in the proximity of specific experiences. Given the low prevalence of many reported stressors within the non-psychological distress cohort, only one experience contingency was identified as significant. The proximity between expressing guilt, and trouble coping was significantly closer within individuals who did not report psychological distress $\mathrm{F}=22.260, p=0.027$.

The next section seeks to understand how risk factors may play a role in disengagement, and post-disengagement for individuals who suffer from psychological distress.

\section{Disengagement}

Chi square and associated Fisher's Exact Tests were conducted to determine associations between psychological distress and risk factors at disengagement and in the post disengagement period. Table 7 shows significant associations.

The results highlight a number of significant associations with psychological distress and reasoning behind disengagement. Individuals with psychological distress were more likely to fear harm from group members $\left(\mathrm{X}^{2}(1)=7.595, p=0.006, \mathrm{OR}=4.831\right)$, and claim that their tasks and roles were too risky $\left(\mathrm{X}^{2}(1)=3.850, p=0.050, \mathrm{OR}=2.786\right)$. $\mathrm{A}$ large difference between individuals was found in the role of burnout at disengagement $\left(\mathrm{X}^{2}(1)=6.487, p=0.011, \mathrm{OR}=4.556\right)$, and religious conversion (Fisher's Exact Test, $p=0.043$ ) only played a role in disengagement within individuals who reported psychological distress. There were no other significant differences identified between the remaining variables concerning reasoning behind disengagement. Particularly pertinent, despite differences in reasoning, there was no difference between psychological distress and a 


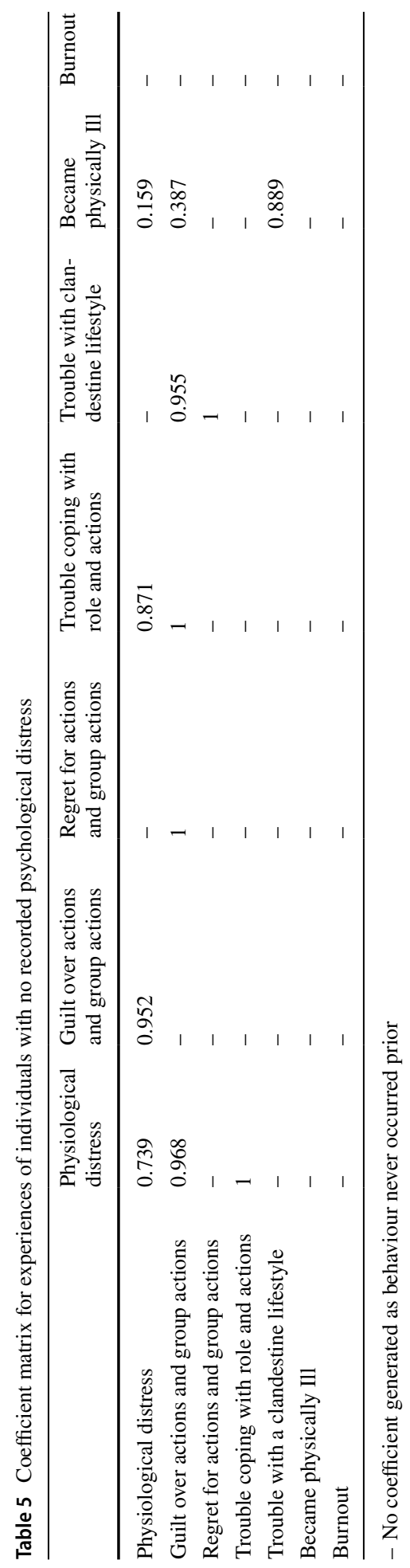




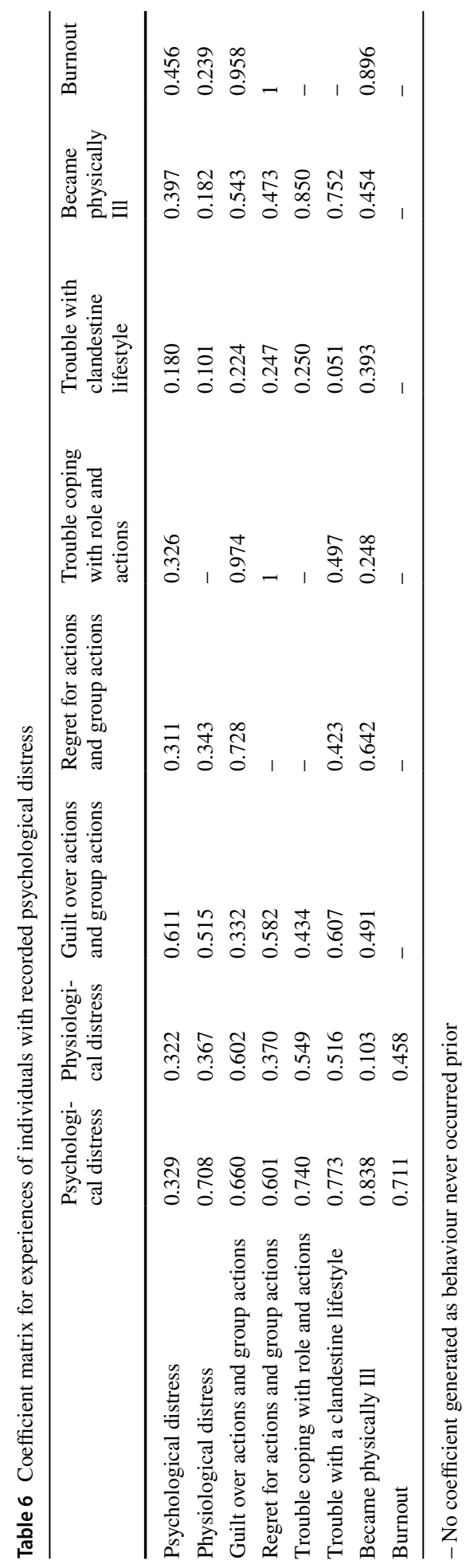


Table 7 Significant associations between stressors and psychological distress

\begin{tabular}{lll}
\hline Experience of distress & $\begin{array}{l}\text { Frequency psychological distress } \\
\mathrm{N}=36(\%)\end{array}$ & $\begin{array}{l}\text { Frequency no psycho- } \\
\text { logical distress } \mathrm{N}=50 \\
(\%)\end{array}$ \\
\hline Disengagement & & \\
Fear harm from group & $26.0^{* *}$ & 6.8 \\
Religious conversion & $10.3^{*}$ & 0.0 \\
Tasks too risky & $33.3^{*}$ & 15.2 \\
Burnout & $30.8^{*}$ & 8.9 \\
Post-disengagement & & \\
Victim of violence & $72.2^{*}$ & 50.0 \\
Expressed regret & $47.2^{* * *}$ & 10.0 \\
Trouble coping & $27.8^{*}$ & 8.0 \\
Fear harm from group & $36.1^{* * *}$ & 8.0 \\
Disillusionment with group strategy & $71.4^{*}$ & 44.9 \\
Guilt & $40.0^{*}$ & 18.4 \\
Burnout & $61.1^{* * *}$ & 22.0 \\
Politics & 14.3 & $38.0 *$ \\
Felt Judged & $44.4^{* *}$ & 18.0 \\
Psychological Support & $13.9^{*}$ & 0.0 \\
\hline
\end{tabular}

$* p<0.05, * * p<0.01, * * * p<0.005$

desire to disengage (46.0\% psychological distress, $44.1 \%$ non-psychological distress, $\mathrm{X}^{2}(1)=0.041, p=0.840$ ), highlighting that although both groups have similar levels of desire to disengage from the group, reasoning for individuals with and without psychological distress is far more complex and varied than bivariate statistics can highlight.

Authors of the autobiographies highlighted the complex, multifaceted nature of reasoning behind disengagement. These reasons included family (Piccolini 2015), dissatisfaction with the actions of the group (McGuire 1973), individual and collective exhaustion (AlHout et al. 2011; Stern 1975), loneliness, and fear (Collins 2002).

Each of the autobiographies not only gave different reasons for disengagement, but described the culmination of multiple experiences which impacted on their decision to disengage. This is also true of experiences in the post-disengagement period. The next section explores negative experiences reported post-disengagement, before examining the proximity coefficients both of risks for disengagement and post-disengagement to identify associations between disengagement decisions and post-disengagement psychological distress.

\section{Post Disengagement}

The earlier literature review highlighted that post-traumatic stress symptoms are the result of behaviors and experiences. Therefore, to examine psychological distress in the post-disengagement period, the analyses focused on individuals' experiences when engaged as well as when disengaged. Table 7 also presents the resulting significant associations between experiences and psychological distress in the post-disengagement period. Individuals who reported psychological distress in the post disengagement period were significantly more likely to be a victim of violence when engaged in terrorism $\left(X^{2}(1)=4.283, p=0.039\right.$, $\mathrm{OR}=2.600)$, express regret for their actions when engaged $\left(\mathrm{X}^{2}(1)=15.233, p=0.000\right.$, 
$\mathrm{OR}=8.053)$, and have trouble coping with their actions when engaged $\left(X^{2}(1)=6.007\right.$, $p=0.014$, $\mathrm{OR}=4.423$ ). These concerns carried into the post-disengagement period, as individuals who suffered psychological distress following disengagement were significantly more likely to fear being a victim of harm from their former group $\left(X^{2}(1)=10.429\right.$, $p=0.001, \mathrm{OR}=6.500),{ }^{9}$ feel guilt for their roles in attacks $\left(\mathrm{X}^{2}(1)=4.805, p=0.028\right.$, $\mathrm{OR}=2.963)$, and report burnout $\left(\mathrm{X}^{2}(1)=13.539, p=0.000, \mathrm{OR}=5.571\right)$.

These experiences had longstanding effects. Individuals were significantly more likely to report feeling judged for their previous activities $\left(\mathrm{X}^{2}(1)=7.099, p=0.008, \mathrm{OR}=3.644\right)$, and were also significantly more likely to receive psychological help (Fisher's Exact Test, $p=0.011$ ). Individuals who experienced psychological distress in the post-disengagement period were also more disconnected from their previous social identity. This is highlighted in significant associations with disillusionment with the strategy of their former group $\left(\mathrm{X}^{2}(1)=5.831, p=0.016, \mathrm{OR}=3.068\right)$, that such individuals were significantly less likely to move into legal politics $\left(\mathrm{X}^{2}(1)=5.714, p=0.017, \mathrm{OR}=0.272\right)$, and they were less likely ${ }^{10}$ to report that they felt their past behavior was morally justifiable $\left(X^{2}(1)=3.441\right.$, $p=0.064$, OR $=0.821$ ).

The above analysis highlighted a number of experiences which may impact upon psychological wellbeing. However, static analytical techniques weight experiences equally. In order to determine which experiences are relevant to psychological distress, it is necessary to examine interactions between experiences across disengagement and post disengagement. Tables 8 and 9 show proximity coefficients for the significant experiences within Table 7.

Although the initial bivariate analyses highlighted a moderate frequency of experiences within individuals who did not report psychological distress, the lack of association across proximity coefficients demonstrate that these experiences may have occurred in isolated circumstances. Only victimisation was consistently associated with disengagement and post disengagement experiences. Within the cohort, moving into legal politics always followed experiences, and was most likely to follow disillusionment with group strategy. In every case, guilt immediately preceded regret and problems coping, but was also closely associated toward a move to politics. Alongside this, feeling judged immediately led to a religious conversion. These results highlight the coping strategies that individuals may employ to help protect from later onset of psychological distress.

The results for individuals who did report psychological distress are far more complex. The results highlight the cyclical nature of psychological distress and guilt, as both were reported both before and after the other experiences. In this cohort, disillusionment with the group strategy was more associated with psychological support than politics, highlighting different coping mechanisms of these individuals. The reporting of feeling judged always followed other negative experiences, and moves into legal politics were also highly likely to follow negative experiences. In this group, feeling judged never preceded religious conversion. Similar to individuals who did not report psychological distress, a move to politics was closely associated with regret and guilt, but in this group, the experience most closely linked to a political career was expression that their tasks within the terrorist group were 'too risky', despite a lesser association between victimization and riskiness than identified in those who did not report distress.

Given the low frequency of many reported experiences within the non-psychologically distressed cohort, only one significant difference in association between groups was found.

\footnotetext{
9 This is contrary to non-significant associations found in fearing becoming a victim from external sources $\mathrm{X}^{2}(1)=0.066, p=0.797$, suggesting previous victimisation may have been group based.

10 Results approached significance.
} 


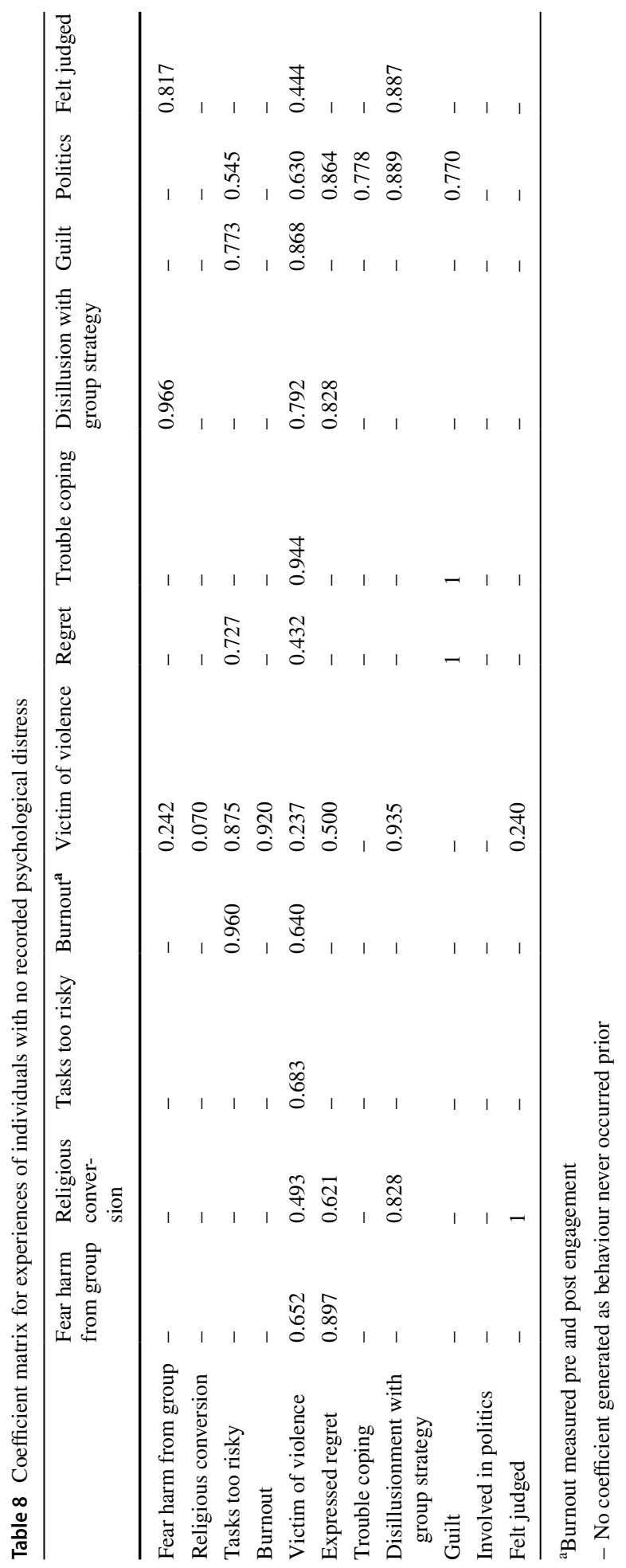




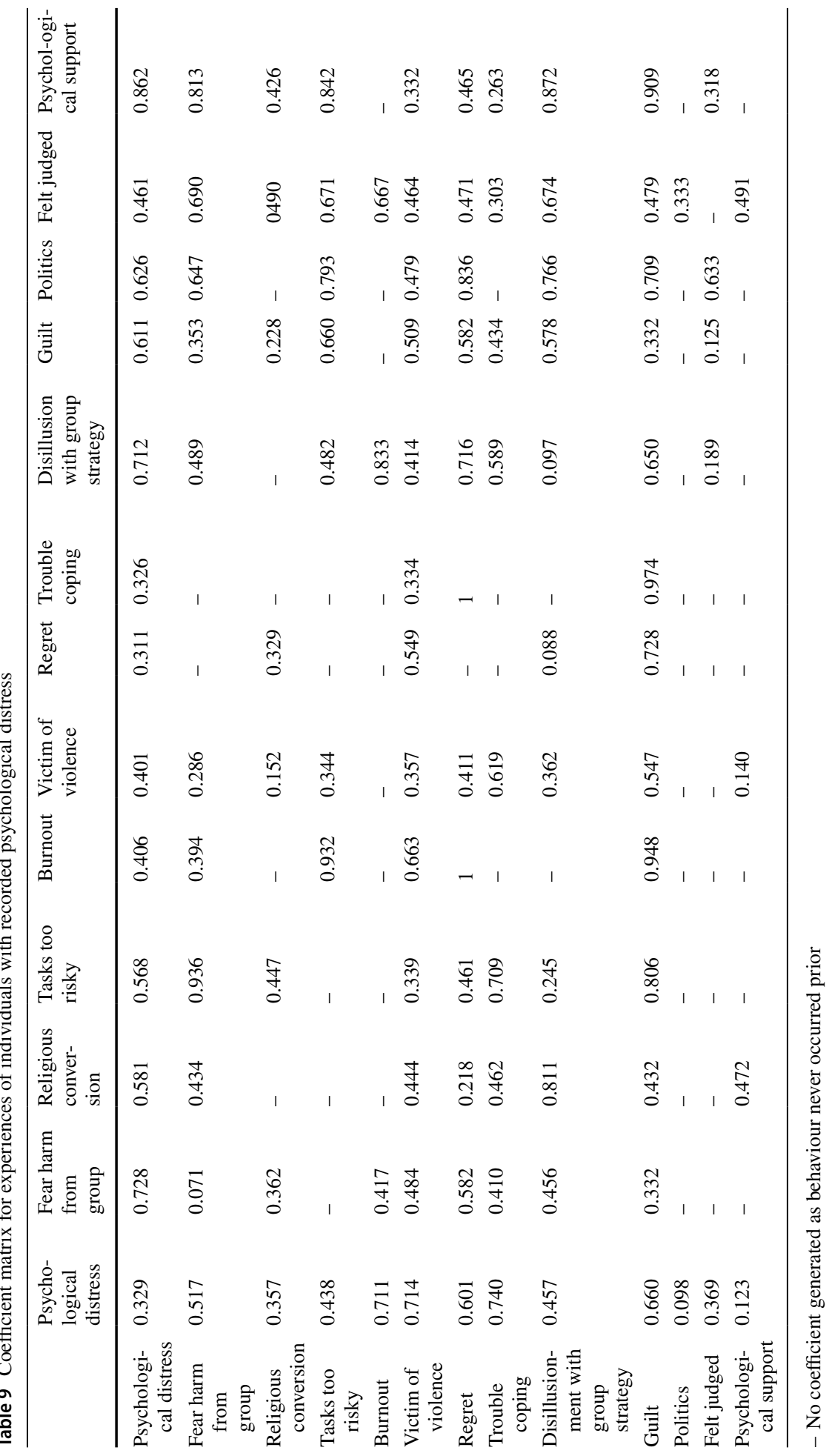


The proximity between guilt and trouble coping was significantly closer within individuals who did not report psychological distress $(\mathrm{F}=22.260, p=0.02)$. One other association between experiences approached significance. The proximity between victimisation, and disillusionment with group strategy was closer within individuals who did not report psychological distress $(\mathrm{F}=3.7504, p=0.09)$.

\section{Discussion}

This paper examined whether; risk factors within terrorist groups increase the likelihood of developing psychopathology (measured as both psychological distress and mental disorder). There is a consensus across current literature that decisions to disengage vary hugely across actors, with multiple factors influencing the final decision to disengage. However, this paper has been the first empirical work to identify the association between these factors, and how journeys through terrorism affect actors' mental wellbeing. This paper identified that risk factors play a role in the psychological consequences of being involved in a terrorist organization. Individuals who reported experiencing psychological distress were significantly more likely to report experiencing a wide range of stressors, and it is the combination of these stressors which have long term consequences for psychopathology.

The prevalence data provides evidence that risk factors and negative experiences during engagement have an effect on mental wellbeing. The prevalence of psychological distress doubles between pre-engagement and engagement, and then decreases following disengagement. These results suggest that the experiences of being engaged in a terrorist group negatively impact on the mental health of a subset of individuals. That the prevalence of psychological distress did not decrease to the baseline level reported prior to engagement implies that the negative experiences during engagement may have longstanding effects, impacting on multiple aspects of an individual's life. This supports Weatherston and Moran (2003). Taking the prevalence data as a starting point, initial inferential analyses examined which risk factors and negative experiences are more likely to be reported within the cohort of individuals who suffer psychological distress.

The initial bivariate analyses indicated that it is not the experience of negative events which impacts on psychopathology, but the actor's interpretation of these events. No significant associations were identified between the actor's experiences of violence, victimization, disrespect, imprisonment, abuse, the loss of a close family member or friend, or substance abuse. However, the differences lay in how the individual coped with these experiences. Individuals who reported psychological distress were significantly more likely to report guilt, regret, problems coping with their actions, problems with their lifestyle, and burnout. These initial results lend support to the argument that within more psychologically resilient individuals, negative experiences do not produce the same levels of distress. However, because twice the number of individuals reported psychological distress during engagement compared to early life experiences suggests other important factors may mediate distress. This difference in prevalence may be explained by identity fusion. Individuals who reported distress were less likely to have undergone identity fusion, as they were significantly more likely to struggle with the actions of the group (Byrne 2003; Turner and Avison 1992).

The proximity coefficients generated for risk factors within terrorist engagement highlight that individuals who did not report psychological distress were not only less likely to report negative experiences and emotions than individuals who did report distress, but these experiences were also more likely to occur in isolation. For individuals who did report distress, 
all experiences impacted on psychopathology. The reporting of distress was more likely to follow negative experiences, but the results also demonstrated the culmination of multiple experiences and the cyclical nature of negative experiences and distress. The results indicated that burnout was a result of multiple negative experiences and distress, and this is further validated in the bivariate analyses which investigated the reasoning behind disengagement. Burnout as a reason for disengagement had the largest frequency disparity between actors.

The evidence also highlights the role of burnout in disengagement, and emphasizes the role of multiple factors impacting on an individual, and how these factors compound to increase a desire to disengage. That no significant differences were found between actors in their desire to disengage from terrorist activities, and the low number of significant differences in reasoning for disengagement, highlights the difficulties in analyzing individual decision making following unique journeys and experiences. The proximity coefficients for these experiences indicate that within the cohort of individuals who did not report psychological distress, the only association identified between experiences highlighted that within this cohort, feeling that a task was too risky almost always preceded burnout. Also of note, though individuals within this cohort were not more likely (than those who reported distress) to express that being a victim whilst engaged was a reason behind disengagement, this experience always preceded the eventual reason, and was more closely associated than the cohort who did report distress. Within individuals who did report psychological distress, much like the negative experiences during engagement, the reasoning for disengagement was far more complex. Fear from group harm preceded all other experiences which could trigger disengagement, however, contrary to the reasoning of (Gunaratna 2009; Swann et al. 2012; Ystgaard et al. 1999), psychological distress was more likely to be reported prior to expression of fear of group harm. This may be because individuals, due to their experiences during engagement (such as guilt, regret, and trouble coping with the actions of themselves and the group) have already broken from their social identity, and the fear of harm was a result of this breakdown. Again, within this cohort, burnout was more likely to be the result of the culmination of multiple reasons and experiences.

The examination of differences between those who did and did not report psychological distress in the post-disengagement phase did not lend support to the work of Haslam and Reicher (2006), Evans et al. (2004), or Donald and Dower (2002) because no significant differences identified in levels of social support post-disengagement. In fact, individuals who reported distress were more likely (though not significantly) to have access to both material (52.8\% compared to $34.0 \%$ ) and emotional (50\% compared to 38\%) support in the post-disengagement period. However, without further analyses, these results are unable to follow the work of Kaniasty and Norris (2008), Keane et al. (1985) and Solomon and Mikulincer (1990), and identify when social support occurred and was removed, and the resulting impact on wellbeing. The results do lend support to the investigations within former Irish Republican and Unionist groups (McEvoy et al. 2004; Jamieson et al. 2010). Individuals who reported distress were significantly more likely to also express that they had guilt, regrets, and trouble coping with their actions, all of which were more likely to precede psychological distress. Guilt was a more consistent factor within negative post-disengagement experiences, and more often preceded regret and problems coping, supporting Crisford et al. (2008) and Leskela et al. (2002).

These conclusions are hampered by the complexity of the quantitative data. The analyses have been limited due to the examination of multiple internal and external factors, and how the presence of these factors impact an individual's psychopathology. During coding, over 200 experiences were examined, and every individual had a different life course and trajectory of experiences. To date, proximity coefficients have been used to examine interactions, with a limited number of experiences within each behavioral chain, the analyses 
within this paper examined far more comprehensive processes. To reduce the noise within the data, bivariate statistics were employed to reduce the amount of experiences examined. This may have reduced the validity and replicability of the results and should be taken into account during interpretation. Given the data constraints, it was also not possible to examine entire life courses, and the results were therefore split into pre-engagement, engagement, and disengagement, with little examination of how these pathways may be linked. Further work should endeavor to examine longer behavioral pathways, and build a more complete picture of entire life courses.

A second limitation concerns the data sources. This investigation used data from autobiographical writings, which were often historical accounts, and biased towards a political genre, which limited the depth of information regarding mental health problems and symptoms. Individuals are often motivated to conceal their mental health status, in order to appear 'normal', and this is particularly true within the autobiographies, who were often using their writings as a platform for their political message. The authors may have been concerned that disclosing their mental state may have portrayed a lack of capability, and even rationality, and readers may have not taken their political message with the seriousness intended. Or they may have simply not deemed their mental state as relevant. It is also worth noting that there are concerns over the factual accuracy of the accounts that were analyzed. Altier et al. (2012, p. 90) explained the potential for bias in autobiographical data.

"authors may legitimize, rationalize, and justify their previous behavior as well as offer propaganda to further a group's "message" and cause."

Authors may be strongly motivated to portray their actions in a favorable light. This risk for inaccuracy over specific events may help to explain the lack of significant differences between specific events and experiences. Authors were often reluctant to concede to being involved in specific events, and this may reduce the validity of the results. However, autobiographical data still affords the opportunity to examine how terrorist's construct their personal and social identities, and make crucial life decisions, as although the individuals may not record direct involvement in specific activities, they were very likely to describe their thoughts and feelings around such incidents. A further bias inherent within autobiographical data concerns the sampling pool. Individuals who are willing to write autobiographies, may in fact be fundamentally different from those who do not write about their experiences. These individuals may not be representative of the huge number of individuals involved within terrorism, and may in fact be outliers. However, this limitation applies to other forms of primary data gathered by terrorism researchers; those who have written autobiographies may also be more receptive to interview techniques.

The autobiographies provide unique insight into the sequencing of life experiences. However, the means through which the autobiographies talked about 'time' was inconsistent between and within autobiographies. In some instances, exact timings were reported (for example, event B happened two weeks after event A). In other instances, they were inexact (for example, event B happened a 'short period' or 'some time' after event A). Had the time-stamping been more consistent, it would have allowed for layering a timeseries analysis over the sequence analyses (Quinn-Evans et al. 2019) or T-system analyses (Casarrubea et al. 2015; Gottman et al. 1977). Other fairly standardized or legally-oriented documents like indictments might be better sources for such endeavors focused on understanding terrorism. A related limitation is that our analysis looked at sequences such as $\mathrm{A} \rightarrow \mathrm{B} \rightarrow \mathrm{C} \rightarrow \mathrm{D}$ and thus only measured the onset of each behaviour. It is of course likely in many instances that behaviours might be concurrent (e.g. 'A' might still be occurring whilst 'B' is) (Keatley 2018, p. 147). More complex (e.g. the aforementioned T-Pattern) 
analyses are possible which test whether the co-occurrence of $\mathrm{AB}$ more often leads to $\mathrm{C}$, however, there are concerns regarding over-fitting of sequences, thus limiting generalisability (Ellis et al. 2017) as well as a "variety of other reasons" (Keatley et al. 2018a, b). This is especially pertinent for this paper given only $90+$ cases are examined; however the sample size is larger than other life-history behavioural sequence analyses (e.g. Keatley et al. 2018a, b). Again, such analyses require discrete time scales which a life course analysis like ours does not have. Indeed, this may be why T-Pattern analyses have "not been used in criminal or forensic research" barring one methodological illustration of it applied to police interview procedures and false confessions (Keatley 2018, p. 150).

Despite these limitations, this paper has offered new, empirical insights into what it is to 'be' a terrorist. The complexity of social and personal experiences that occur during a lifespan has highlighted that the social connections groups may have, play a protective role for buffering against psychological distress. However, this paper has also indicated that for a subset of individuals, the inherent risk factors and negative experiences encountered during engagement may have a longstanding impact on psychopathology. The results provide important implications, which current de-radicalization and disengagement programs should consider. Psychological distress spanning from involvement within a terrorist group impacts a significant proportion of individuals well after disengagement. For these individuals, de-radicalization and disengagement programs conducted over a limited time period may not be sufficient to alleviate distress.

\section{Conclusion}

This paper provided empirical evidence that the current common opinion that individuals involved in terrorist groups do not suffer from psychopathology needs to be reconsidered. Individuals engaged within terrorism encounter a number of risk factors, which if an individual has lower baseline levels of individual psychological resilience and is not fully committed to the group identity, may impact them psychologically. The results highlighted that it is not the presence of risk factors which impact on an individual, but how they perceive these risk factors. The results helped highlight the complexity of 'being' a terrorist. Multiple factors at individual, social, and group levels impact on an individual as they pass through life. The results have confirmed that dichotomous opinions and statements such as "It's a group phenomenon. To search for individual characteristics in order to understand them is misleading. It will lead you to a dead end" (Sageman, cited by Rotella 2004) need to be seriously reconsidered. A large number of individuals self-reported instances of severe psychological distress over multiple points in their lifespans, which in some cases was compounded by their disagreement over the actions of the group.

Open Access This article is distributed under the terms of the Creative Commons Attribution 4.0 International License (http://creativecommons.org/licenses/by/4.0/), which permits unrestricted use, distribution, and reproduction in any medium, provided you give appropriate credit to the original author(s) and the source, provide a link to the Creative Commons license, and indicate if changes were made. 


\section{Appendix 1}

Groups within Autobiograhies

- African National Congress

- Arabic Nationalist Movement

- Confederación Nacional del Trabajo

- Communist Party of Germany

- Direct Action

- Fatah

- Frente Sandinista Liberacion Nacional

- Glasgow Anarchist Group

- Hamas

- Harakat-ul Jihad

- Iberian Federation of Libertarian Youth

- Irish National Liberation Army

- Irish Republican Brotherhood

Kenya African Union

Lehi

- Lord's Resistance Army

- Mau Mau

- Moveimiento 19 de Abril

- MPLA

- Northern Hammer Skinheads

- African Resistance Movement

- National Socialist German Workers Party

- Provisional Irish Republican Army

- Polish Underground

- Red Hand Commando

Seattle Liberation Front

- South African Communist Party

- Spartacus League

- The Weathermen

- Ulster Volunteer Force

- Xhi

a The Covenant Sword and Arm of the Lord
- American Firm

- Chicago Area Skinheads

- Communist Party of the Philippines

- Cumann na mBan

- Ethniki Organosis Kyprion Agoniston

- Front de libération du Québec

- Front de Liberation du Quebec

Groupe Islamique Arme

- Hammerskins

- Hizb ut-Tahrir

- Irgun Zvai Leumi

- Irish Republican Army

Irish Volunteers

Ku Klux Klan

- Lithuanian Freedom Council

- Umkhonto we Sizwe

- Minutemen

- Movement of the 30th of January

- Muslim Brotherhood

Na Fianna

- The National Alternative

- Popular Front for the Liberation of Palestine

- Palestine Liberation Organisation

- Red Army Faction

Romantic Violence

Skinhead Army of Milwaukee

- South African Indian Congress

- South West African People's Organisation

- Ulster Defence Association

- June 2nd Movement

- Jama-e-Islami

- Zimbabwe African People's Union

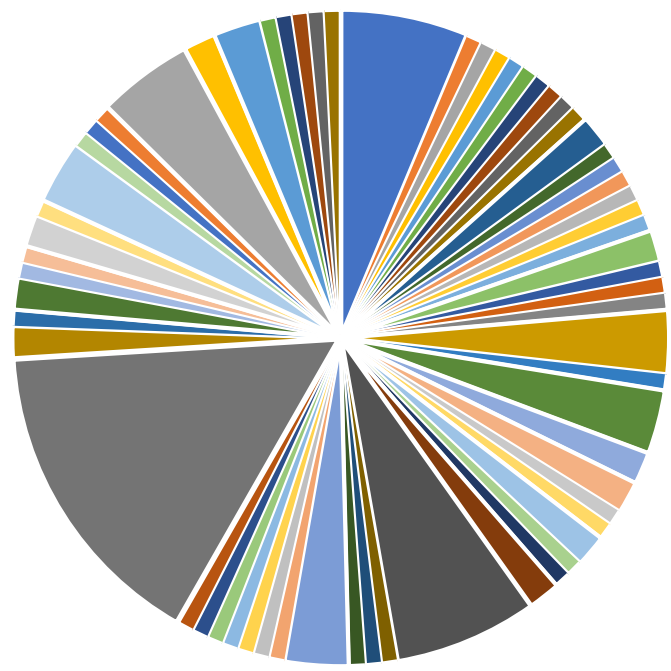




\section{References}

Al-Hout S, Makdisi JS, Asser M (2011) My life in the PLO: the inside story of the Palestinian struggle. Pluto Press, London, England

Altier MB, Horgan J, Thoroughgood C (2012) In their own words? Methodological considerations in the analysis of terrorist autobiographies. J Strateg Secur 5(4):85-98

Altier MB, Leonard Boyle E, Shortland ND, Horgan JG (2017) Why they leave: an analysis of terrorist disengagement events from eighty-seven autobiographical accounts. Secur Stud 26(2):305-332

American Psychiatric Association (APA) (2013) Diagnostic and statistical manual of mental disorders, fifth edition. Arlington, VA, American Psychiatric Publishing

Berney LR, Blane DB (1997) Collecting retrospective data: accuracy of recall after 50 years judged against historical records. Soc Sci Med 45(10):1519-1525

Beune K, Giebels E, Taylor PJ (2010) Patterns of interaction in police interviews: the role of cultural dependency. Crim Justice Behav 37(8):904-925

Borum R (2011) Understanding terrorist psychology. In: Silke A (ed) The psychology of counter-terrorism. Routledge, Oxon, pp 19-33

Broadhead WE, Kaplan BH, James SA, Wagner EH, Schoenbach VV, Grimson R et al (1983) The epidemiologic evidence for a relationship between social support and health. Am J Epidemiol 117(5):521-537

Byrne MK (2003) Trauma reactions in the offender. Int J Forensic Psychol 1(1):59-70

Cabezas O (1985) Fire from the mountain: the making of a Sandinista. Jonathan Cape, London

Casarrubea M, Jonsson GK, Faulisi F, Sorbera F, Di Giovanni G, Benigno A et al (2015) T-pattern analysis for the study of temporal structure of animal and human behavior: a comprehensive review. J Neurosci Methods 239:34-46

Collins A (2002) My jihad: The true story of an American mujahid's amazing journey from Usama Bin Laden's training camps to counterterrorism with the FBI and CIA. Lyon Press, Guilford

Collins E (1998) Killing Rage. London, England, Granta Publications

Collins English Dictionary (2015) Retrieved from http://www.collinsdictionary.com/dictionary/english

Conway MA, Haque SS (1999) Overshadowing the reminiscence bump: memories of the struggle for independence. J Adult Dev 6(1):35-44

Conway MA, Pleydell-Pearce CW (2000) The construction of autobiographical memories in the self-memory system. Psychol Rev 107(2):261-288

Corbin JM, Strauss A (1990) Grounded theory research: procedures, canons, and evaluative criteria. Quant Sociol 13(1):3-21

Cordes B (1987) When terrorists do the talking: reflections on terrorist literature. J Strateg Stud 10(4):150-171

Corner E, Gill P (2015) A false dichotomy? Mental illness and lone-actor terrorism. Law Hum Behav 39(1):23

Corner E, Gill P, Mason O (2016) Mental health disorders and the terrorist: a research note probing selection effects and disorder prevalence. Stud Confl Terror 6:560-568

Corner E, Bouhana N, Gill P (2019) The multifinality of vulnerability indicators in lone-actor terrorism. Psychol Crime Law 25(2):111-132

Crenshaw M (1991) How terrorism declines. Terror Polit Violence 3(1):69-87

Crisford H, Dare H, Evangeli M (2008) Offence-related posttraumatic stress disorder (PTSD) symptomology and guilt in mentally disordered violent and sexual offenders. J Forensic Psychiatry Psychol 19(1):86-107

Cronin AK (2006) How al-Qaida ends: the decline and demise of terrorist groups. Int Secur 31(1):7-48

Cronin AK (2009) How terrorism ends: understanding the decline and demise of terrorist campaigns. Princeton University Press, Princeton

Daumantas J (1975) Fighters for freedom: Lithuanian partisans versus the U.S.S.R. 1944-1947. Maryland Books, New York

Demant F, Slootman M, Buijs F, Tillie J (2008) Decline and disengagement: an analysis of processes of deradicalization. Institute for Migration and Ethnic Studies, Amsterdam

Dingake M (1987) My fight against apartheid. Kliptown Books, London

Donald M, Dower J (2002) Risk and protective factors for depressive symptomology among a community sample of adolescents and young adults. Aust N Z J Public Health 26(6):555-562

Ellis HE, Clarke DD, Keatley DA (2017) Perceptions of behaviours in stranger rape cases: a sequence analysis approach. J Sex Aggress 23(3):328-337

Evans J, Middleton N, Gunnell D (2004) Social fragmentation, severe mental illness and suicide. Soc Psychiatry Psychiatr Epidemiol 39(3):165-170 
Fossi JJ, Clarke DD, Lawrence CL (2005) Bedroom rape: sequences of sexual behavior in stranger assaults. J Interpers Violence 20(11):1444-1466

Freudenberger HJ (1974) Staff Burn-Out. J Soc Issues 30(1):159-165

Fulton K (2008) Unsung hero: How I saved dozens of lives as a secret agent inside the IRA. John Blake Publishing, London

Giebels E, Taylor PJ (2009) Interaction patterns in crisis negotiations: persuasive arguments and cultural differences. J Appl Psychol 94(1):5-19

Gill P, Corner E (2013) Disaggregating terrorist offenders: implications for research and practice. Criminol Pub Policy 12:93

Gill P, Corner E (2017) There and back again: the study of mental disorder and terrorist involvement. Am Psychol 72(3):231

Gill P, Horgan J, Deckert P (2014) Bombing alone: tracing the motivations and antecedent behaviors of lone-actor terrorists. J Forensic Sci 59(2):425-435

Gottman J, Markman H, Notarius C (1977) The topography of marital conflict: a sequential analysis of verbal and nonverbal behavior. J Marriage Fam 39(3):461-477

Gunaratna R (2009) The battlefield of the mind: rehabilitating Muslim terrorists. UNISCI Discuss Pap 21:148-163

Haslam SA, Reicher S (2006) Stressing the group: social identity and the unfolding dynamics of responses to stress. J Appl Psychol 91(5):1037-1052

Hasselbach I, Reiss T (1996) Fuhrer-ex: memoirs of a former neo-Nazi. Random House, New York

Hobfoll SE, Canetti-Nisim D, Johnson RJ (2006) Exposure to terrorism, stress-related mental health symptoms, and defensive coping among Jews and Arabs in Israel. J Consult Clin Psychol 74(2):207-218

Horgan J (2009) Walking away from terrorism: accounts of disengagement from radical and extremist movements. Routledge, Abingdon

Jamieson R, Shirley R, Grounds A (2010) Ageing and social exclusion among former politically motivated prisoners in Northern Ireland. Report for the Changing Ageing Partnership, Institute of Governance, School of Law, Queens University Belfast

Jones SG, Libicki MC (2008) How terrorist groups end: lessons for countering al Qa'ida. RAND, Santa Monica

Kaniasty K, Norris FH (2008) Longitudinal linkages between perceived social support and posttraumatic stress symptoms: sequential roles of social causation and social selection. J Trauma Stress 21(3):274-281

Keane TM, Scott WO, Chavoya GA, Lamparski DM, Fairbank JA (1985) Social support in Vietnam veterans with posttraumatic stress disorder: a comparative analysis. J Consult Clin Psychol 53(1):95-102

Keatley D (2018) Pathways in crime: an introduction to behaviour sequence analysis. Springer, Berlin

Keatley DA, Golightly H, Shephard R, Yaksic E, Reid S (2018a) Using behavior sequence analysis to map serial killers' life histories. J Interpers Violence. https://doi.org/10.1177/0886260518759655

Keatley DA, Marono A, Clarke DD (2018b) Unmaking a murderer: behaviour sequence analysis of false confessions. Psychiatry Psychol Law 25(3):425-436

Kessler RC, Üstün TB (2008) The WHO world mental health surveys: global perspectives on the epideminology of mental disorders. Cambridge University Press, Cambridge

Kessler RC, Price RH, Wortman CB (1985) Social factors in psychopathology: stress, social support, and coping processes. Annu Rev Psychol 36(1):531-572

Kotler M, Iancu I, Efroni R, Amir M (2001) Anger, impulsivity, social support, and suicide risk in patients with posttraumatic stress disorder. J Nerv Mental Dis 189(3):162-167

Krippendorff K (2004) Reliability in content analysis: some common misconceptions and recommendations. Human Commun Res 30(3):411-433

Lafree G, Jensen MA, James PA, Safer-Lichtenstein A (2018) Correlates of violent political extremism in the united states. Criminology 00:1-36

Leskela J, Diepernik M, Thuras P (2002) Shame and posttraumatic stress disorder. J Trauma Stress 15(3):223-226

Li X, Howard D, Stanton B, Rachuba L, Cross S (1998) Distress symptoms among urban African American children and adolescents: a psychometric evaluation of the checklist of children's distress symptoms. Arch Pediatric Adolesc Med 152(6):569-577

Mandela N (1995) Long walk to freedom. Abacus, London

McCauley C, Moskalenko S (2008) Mechanisms of political radicalization: pathways toward terrorism. Terror Political Violence 20(3):415-433

McEvoy K, Shirlow P, McElrath K (2004) Resistance, transition and exclusion: politically motivated exprisoners and conflict transformation in Northern Ireland. Terror Political Violence 16(3):646-670 
McGuire M (1973) To take arms: A year in the Provisional IRA. London, England, Macmillan

Merari A (2010) Driven to death: psychological and social aspects of suicide terrorism. Oxford University Press, Oxford

Miller E (2012) Patterns of onset and decline among terrorist organizations. J Quant Criminol 28(1):77-101

Muldoon OT, Lowe RD (2012) Social identity, groups, and post-traumatic stress disorder. Polit Psychol 33(2):259-273

Mullins S (2010) Rehabilitation of Islamist terrorists: lessons from criminology. Dyn Asymmetric Confl $3(3): 162-193$

Nasiri O (2006) Inside the global jihad: How I infiltrated Al Qaeda and was abandoned by Western intelligence. C. Hurst, London

Neuner F, Pfeiffer A, Schauer-Kaiser E, Odenwald M, Elbert T, Ertl V (2012) Haunted by ghosts: prevalence, predictors and outcomes of spirit possession experiences among former child soldiers and waraffected civilians in Northern Uganda. Soc Sci Med 75(3):548-554

Piccolini C (2015) Romantic violence: memoirs of an American Skinhead. Goldmill Group, Chicago

Quinn-Evans L, Keatley DA, Arntfield M, Sheridan L (2019) A behavior sequence analysis of victims' accounts of stalking behaviors. J Interpers Violence. https://doi.org/10.1177/0886260519831389

Reinares F (2011) Exit from terrorism: a qualitative empirical study on disengagement and deradicalization members of ETA. Terror Polit Violence 23(5):780-803

Ross JI (2004) Taking stock of research methods and analysis on oppositional political terrorism. The American Sociologist 35(2):26-37

Ross JI, Gurr TR (1989) Why terrorism subsides: a comparative study of Canada and the United States. Comp Politics 21(4):405-426

Rotella S (2004) Social Bonds Pull Muslim Youth to Jihad, Expert Says, Los Angeles Times. Retrieved from http://articles.latimes.com

Rubin TA, Wetzler SE, Nebes RD (1986) Autobiographical memory across the lifespan. In: Rubin DC (ed) Autobiographical memory. Cambridge University Press, Cambridge, pp 202-224

Rubin DC, Rahhal TA, Poon LW (1998) Things learned in early adulthood are remembered best. Mem Cognit 26(1):3-19

Schützwohl M, Maercker A (2000) Anger in former East German political prisoners: relationship to posttraumatic stress reactions and social support. J Nerv Mental Dis 188(8):483-489

Shapiro JN (2013) The terrorist's dilemma. Princeton, NJ, Princeton University Press

Solomon Z, Mikulincer M (1990) Life events and combat-related posttraumatic stress disorder: the intervening role of locus of control and social support. Mil Psychol 2(4):241-256

Stern S (1975) With the Weathermen: the personal journey of a revolutionary woman. Doubleday \& Company, Garden City

Swann WB, Jetten J, Gomez A, Whitehouse H, Bastian B (2012) When group membership gets personal: a theory of identity fusion. Psychol Rev 119(3):441-456

Taylor PJ (2006) Proximity coefficients as a measure of interrelationships in sequences of behavior. Behav Res Methods 38(1):32-50

Taylor PJ, Donald I (2007) Testing the relationship between local cue-response patterns and the global structure of communication behaviour. Br J Soc Psychol 46(2):273-298

Taylor PJ, Jacques K, Giebels E, Levine M, Best R, Winter J, Rossi G (2008) Analysing forensic processes: taking time into account. Issues Forensic Psychol 8:45-57

Taylor O, Keatley DA, Clarke DD (2017) A behavior sequence analysis of perceptions of alcohol-related violence surrounding drinking establishments. J Interpers Violence. https://doi.org/10.1177/08862 60517702490

Thoits PA (1995) Coping, and social support processes: Where are we? What next?. J Health Soc Behav (Extra Issue: forty years of medical sociology: the state of the art and directions for the future), pp 53-79

Turner RJ, Avison WR (1992) Innovations in the measurement of life stress: crisis theory and the significance of event resolution. J Health Soc Behav 33(1):36-50

Ucros CG (1989) Mood state-dependent memory: a meta-analysis. Cogn Emot 3(2):139-167

United States Institute of Peace (1999) How terrorism ends (Special Report No. 48), United States Institute of Peace, Washington

Viera AJ, Garrett JM (2005) Understanding interobserver agreement: the Kappa statistic. Fam Med 37(5):360-363

Wadman R, Clarke D, Sayal K, Armstrong M, Harroe C, Majumder P et al (2017) A sequence analysis of patterns in self-harm in young people with and without experience of being looked after in care. Br J Clin Psychol 56(4):388-407 
Walker RW, Vogl RJ, Thompson CP (1997) Autobiographical memory: unpleasantness fades faster than pleasantness over time. Appl Cognit Psychol 11(5):399-413

Weatherston D, Moran J (2003) Terrorism and mental illness: Is there a relationship? Int J Offender Ther Comp Criminol 47(6):698-713

Wilson AE, Ross M (2001) From chump to champ: people's appraisals of their earlier and present selves. J Pers Soc Psychol 80(4):572-584

World Health Organisation (WHO) (2010) ICD-10: International statistical classification of diseases and related health problems (10th rev). Retrieved from http://www.who.int/classifications/icd/en/

Yousef MH (2010) Son of Hamas. Authentic Media, Milton Keynes

Ystgaard M, Tambs K, Dalgard OS (1999) Life stress, social support and psychological distress in late adolescence: a longitudinal study. Soc Psychiatry Psychiatr Epidemiol 34(1):12-19

Zerach G, Solomon Z, Horesh D, Ein-Dor T (2013) Family cohesion and posttraumatic intrusion and avoidance among war veterans: a 20-year longitudinal study. Soc Psychiatry Psychiatr Epidemiol 48(2):205-214

Publisher's Note Springer Nature remains neutral with regard to jurisdictional claims in published maps and institutional affiliations. 